Portland State University

PDXScholar

6-16-2021

\title{
Fostering Connectedness Amidst Crisis: LGBTQ Communities in 2020
}

Daniel Leister-Gray

Portland State University

Follow this and additional works at: https://pdxscholar.library.pdx.edu/honorstheses

Part of the Lesbian, Gay, Bisexual, and Transgender Studies Commons, and the Psychology Commons Let us know how access to this document benefits you.

\section{Recommended Citation}

Leister-Gray, Daniel, "Fostering Connectedness Amidst Crisis: LGBTQ Communities in 2020" (2021). University Honors Theses. Paper 1057.

https://doi.org/10.15760/honors.1083

This Thesis is brought to you for free and open access. It has been accepted for inclusion in University Honors Theses by an authorized administrator of PDXScholar. Please contact us if we can make this document more accessible: pdxscholar@pdx.edu. 
Fostering Connectedness Amidst Crisis: LGBTQ Communities in 2020

\author{
by \\ Danny Leister-Gray
}

An undergraduate honors thesis submitted in partial fulfillment of the requirements for the degree of

Bachelor of Science

in

University Honors

and

Psychology

Thesis Advisor:

Dr. Bill Griesar

Portland State University 


\begin{abstract}
The purpose of this thesis was to investigate LGBTQ communities' responses to the global and national crises that took place in 2020. To accomplish this, the thesis ties together and summarizes relevant multidisciplinary constructs, and highlights specific examples of the actions taken by LGBTQ communities in 2020 . The secondary goal was to tell an anecdote providing ecological validity for relevant empirical data. The thesis is informed by LGBTQ psychology, medical sociology, LGBTQ history, modern events, neuroendocrinology, and neuroscience. The paper concludes that LGBTQ communities used activism, internet, and music to embody resilience and solidarity during 2020. The paper aims to provide a foundation for future research avenues, especially concerning the relationship between the COVID-19 pandemic and LGBTQ communities. Implications and limitations for both the thesis and existing research will be discussed.
\end{abstract}

Keywords: COVID-19 Pandemic, LGBTQ, Minority Stress, SGM, HPA Axis, Cortisol, BLM, Activism, Internet, Music, Neuroendocrinology, Neuroscience

\title{
Introduction
}

Multiple crises simultaneously plagued the US in 2020, including the COVID-19 pandemic, political turmoil, and civil unrest over racial injustice and police brutality. While all of these issues precede (or continue beyond) 2020, this was the year when these crises first simultaneously exploded in ways that affected every single American. This project explores how LGBTQ communities responded to the impacts of these crises, especially the COVID-19 pandemic. By applying multidisciplinary evidence to real-world phenomena, the paper exhibits how LGBTQ communities embody resilience and foster community in trying times. In doing so, it tells an anecdote providing ecological validity for relevant empirical data. In this case, LGBTQ 
communities appeared to utilize activism, internet, and music to foster community and cope throughout 2020. A range of academic constructs inform this thesis, including LGBTQ psychology, medical sociology, social neuroscience, LGBTQ history, modern events, and the psychology and neuroscience of music.

The paper begins by explaining the context of 2020 events and how it relates to LGBTQ communities. It then explores LGBTQ minority stress and protective factors (i.e., community connectedness), and finally, highlights and describes the three major mechanisms of 2020 LGBTQ resilience: activism, internet, and music. Due to the complex and multidisciplinary nature of the paper, it only scratches the surface of the issues addressed. Limitations and implications of the paper, and of existing research, will be discussed.

The construct at hand is valuable, even though the project does not produce empirical, generalizable data. The paper draws influence from multiple disciplines to explain how LGBTQ minorities embodied resilience and adapted to a trying year, and in doing so, applies empirical evidence to everyday reality. This supports the importance and social relevance of these areas of research. Furthermore, it contributes to a new and growing construct: the investigation of COVID-19's impacts on minority communities, and their responses to these impacts.

\section{The Context: 2020 \& LGBTQ Communities}

2020 contained an abundance of challenges that posed additional risk factors to vulnerable communities in the United States. The political climate was notably divided and chaotic, amidst a re-election year with the conservative, highly controversial Trump administration. The murder of George Floyd by Minneapolis police officers (Burch \& Eligon, 2020) triggered civil unrest as it provided momentum for widespread Black Lives Matter protests, a movement against racial injustice dating back to 2013 (McCoy, 2020). However, the 
most global, omnipresent, and widely discussed crisis of 2020 was the (ongoing) COVID-19 pandemic.

The COVID-19 pandemic claimed one million lives worldwide by late September, and the global death toll was rapidly approaching two million by the end of 2020 (Santora \& Wolfe, 2021). During 2020, more than 330,000 Americans died due to COVID-19 complications (National Center for Health Statistics \& CDC, 2021). By October, COVID-19 was the third leading cause of death in the US for people between the ages of 45 and 84, and the second leading cause of death for those 85 years and older (Woolf et al., 2020).

Ultimately, the pandemic impacted nearly every area of life throughout 2020 . The implications of the virus immediately led to skyrocketing unemployment throughout the country (Green et al., 2020), and some scholars feared the impact of COVID-19 on housing instability for LGBTQ individuals (Green et al., 2020; Rodriguez-Seijas et al., 2020). Many individuals suffered from increased mental health problems, anxiety about physical health, and fear of infection (Rodriguez-Seijas et al., 2020; Sauer et al., 2020). In addition, the detrimental impacts of psychosocial isolation ran especially deep for LGBTQ youth, many of whom already experience family rejection, feelings of isolation, and higher rates of mental health disorders (Green et al., 2020; Rodriguez-Seijas et al., 2020).

Beyond the effects of psychosocial isolation, there was concern that LGBTQ individuals' health and safety may be disproportionately impacted by the virus and its implications on everyday life. Generally, LGBTQ individuals experience higher rates of unemployment, housing instability, poverty, food insecurity, and lack of healthcare insurance. They are also more likely to be employed within industries that are impacted by the virus or pose a higher risk of infection (Green et al., 2020; Rodriguez-Seijas et al., 2020). As a result, it is concerning to note how the 
physical health disparities between LGBTQ individuals and their counterparts may lead to a higher likelihood of immune dysfunction, respiratory dysfunction, health comorbidities (Flentje et al., 2020), and thus, potentially serious consequences from COVID-19 infection. To make matters worse, Casey and colleagues (2020) indicate that more than one in six LGBTQ adults report avoiding healthcare visits due to anticipated and experienced discrimination in healthcare settings -- this trend is even higher in transgender adults. Unfortunately, without medically necessary healthcare, transgender individuals appear to experience higher rates of depression, self-harm, and suicidality (Hughto et al., 2015).

In addition, literature documents the negative psychological, physiological, and physical health impacts of social isolation on LGBTQ individuals (Chang et al., 2020; Hatzenbuehler \& McLaughlin, 2014; Newcomb et al., 2020). Recent data suggests that LGBTQ individuals experience less social support than their heterosexual, cisgender (non-transgender) counterparts (Chang et al., 2020; Newcomb et al., 2020). In addition, they experience more peer victimization, parental angry outbursts (Kiekens et al., 2020), and identity-based violence (Newcomb et al., 2020). This can in turn produce greater difficulties with emotion dysregulation, suicide attempts (Chang et al., 2020), and other mental/physical health disparities (Kiekens et al., 2020; Newcomb et al., 2020; Rodriguez-Seijas et al., 2020).

Community advocates in 2020 expressed concern that social isolation within the LGBTQ community can lead to lack of social buffering against negative family interactions, in addition to loss of crucial resources, such as LGBTQ community centers (Green et al., 2020; Kuhr, 2020). Further, a recent study by Rodriguez-Seijas and colleagues (2020) documented higher levels of depression symptoms in LGBTQ individuals compared to their counterparts across the duration 
of 2020. Additionally, higher levels of depression were associated with increased isolation across all groups.

The stressors plaguing LGBTQ communities were compounded by the consistent damage done to LGBQ rights and safety by the 2016-2020 Trump administration (Biskupic, 2020; Cameron, 2020; Gonzalez et al., 2018; Santos et al., 2020; Simmons-Duffin, 2020). Among conservative leaders' numerous attempts to undermine LGBTQ rights included campaigns against transgender bathroom rights, discrimination protections for federal LGBTQ employees (Gonzalez et al., 2018), and gay marriage rights (Biskupic, 2020). They also encouraged transgender homeless discrimination (Cameron, 2020; Santos et al., 2020), and removal of transgender and LGBTQ healthcare protections (Gonzalez et al., 2018; Simmons-Duffin, 2020). These attacks on healthcare protections are especially dire in the context of a deadly pandemic where healthcare rights are more important than ever.

Data suggests that official anti-LGBTQ policies can have negative long-term effects on LGBTQ mental health and well-being (Gonzales \& Ehrenfeld, 2018; Frost \& Fingerhut, 2016; Hatzenbuehler \& McLaughlin, 2014; Hatzenbuehler et al., 2010). This includes lack of protections against nondiscrimination in housing (Gonzales \& Ehrenfeld, 2018) and employment, same-sex marriage bans, and lack of protections against hate crimes (Frost \& Fingerhut, 2016; Hatzenbuehler \& McLaughlin, 2014; Hatzenbuehler et al., 2010). Additionally, however, it seems that even the mere exposure to daily anti-LGBTQ campaign messages which haven't reached policy status can have negative long-term effects on LGBTQ individuals' mental health, physical health, personal and relational well-being, and sense of safety in their communities (Frost \& Fingerhut, 2016; Gonzalez et al., 2018). In light of this data, it is unsurprising that LGBTQ peoples' well-being had been impacted by Trump's administration as 
far back as his 2016 election, which increased LGBTQ distress and vigilance, symptoms of depression and anxiety (Gonzalez et al., 2018), concern and loss of optimism about the future of LGBTQ rights/harrassment/discrimination (Hirsch et al., 2017), and daily lived experiences of anti-LGBTQ discrimination and harrassment (Gonzalez et al., 2018; Human Rights Campaign Foundation, 2017).

Between cumulative stress resulting from the Trump administration, barriers to healthcare, exposure to family rejection, loss of in-person community support and resources, and a potentially higher risk of infection during the COVID-19 pandemic, it was (and still is) more important than ever for LGBTQ communities to embody resilience and solidarity. Fortunately, these skills have been embodied by LGBTQ communities for decades, including activist efforts and community connection during the 1969 Stonewall Uprising (Guarino, 2019; Haber, 2019; Helibroner \& Davis, 2010; Pilkington, 2019) and responses to the 2016 election (Gonzalez et al., 2018; Hirsch et al., 2017). Ultimately, Rodriguez-Seijas and colleagues (2020) documented LGBTQ resilience in 2020 via virtual community involvement. Furthermore, the latter half of this paper will highlight the use of activism, internet, and music by LGBTQ communities in response to the crises of 2020.

\section{Sexual and Gender Minority (SGM) Stress \& Protective Factors}

Meyer first laid the groundwork for the minority stress model when he proposed that anti-LGB stigma, prejudice, and discrimination creates stressful environments for sexual minorities, leading to increased rates of mental health problems (2003). He later clarified that his model expands to gender minorities (i.e., transgender individuals) (Meyer, 2015). As a result, this paper will use the term "sexual and gender minority (SGM) stress," rather than sexual minority stress. SGM may also be used interchangeably when referencing LGBTQ individuals. 
In his 2003 paper, Meyer describes minority stress as unique to stigmatized people, chronic, and socially based. Furthermore, specific stressors may include external anti-SGM environments, expectations of anti-SGM events/harassment/violence, vigilance, internalization of stigma, and concealment of SGM identity (Meyer, 2003). Anti-SGM environmental conditions may include anti-LGBTQ laws, anti-LGBTQ interpretation of religion, family rejection, and hate crimes (Bogart et al., 2013). Furthermore, LGBTQ Americans' experiences of anti-SGM events may include microaggressions, housing and healthcare discrimination (especially against transgender people), and obstacles with employment and the legal system (especially for LGBTQ people of color) (Casey et al., 2019). Unfortunately, data suggests that sexual minority stressors, such as the aforementioned examples, may affect physical health by negatively impacting processes such as immune, cardiovascular, and endocrine systems (Bogart et al., 2013; Flentje et al., 2020).

Hatzenbuehler's psychological mediation framework elaborates on the minority stress model by attempting to explain the intra- and interpersonal mechanisms through which stigma and anti-SGM stressors can affect mental health and psychopathology. He states that anti-SGM stigma produces increased exposure to stress for LGBTQ individuals, which can raise levels of emotion dysregulation, interpersonal problems, and psychological risk factors. These processes in turn mediate the relationship between stigma-related stress and psychopathology (2009). Additionally, stress caused by structural anti-SGM stigma may be compounded by intra- and interpersonal stigma. Overall, this can increase risk for mental and behavioral health problems among SGM (Hatzenbuehler, 2017).

Substantial evidence supports the existence of health disparities between LGBTQ and non-LGBTQ populations. LGBTQ populations suffer from higher rates of psychological distress 
and mental health problems, such as mood and anxiety disorders (Cochran et al., 2003; Medley et al., 2016; Meyer, 2003), and emotion dysregulation (Chang et al., 2020). In addition, behavioral health problems like higher rates of suicidality (Chang et al., 2020; Johns et al., 2019; Meyer, 2003; Newcomb et al., 2020), non-suicidal self-injury (Hughto et al., 2015), and substance use/abuse impact LGBTQ communities (Medley et al., 2016). Lastly, a greater variety of physical health conditions trouble LGBTQ communities (Cochran \& Mays, 2007). Flentje and colleagues (2020) cite a variety of sources documenting poorer health in SGM, including asthma, weakened immune function, and higher incidence of respiratory infection.

Neuroendocrinology research supports the minority stress model, especially via studies on SGM stressors and HPA axis dysregulation. The HPA axis is a complex set of neuroendocrine processes which lead to the secretion of cortisol, a crucial stress hormone (Appendix A). As a result, HPA axis dysregulation results in cortisol dysregulation. Research suggests that, for LGBTQ individuals, growing up in anti-SGM environments impacts HPA axis activity and cortisol production in a way that resembles the physiological effects of traumatic life experiences (DuBois et al., 2017; Hatzenbuehler, 2017; Hatzenbuehler \& McLaughlin, 2014; Parra \& Hastings, 2018). Cortisol production throughout the day is a normal process, but HPA axis dysregulation (like the patterns seen in SGM stress), can result in a variety of abnormal cortisol patterns. This may include blunted cortisol responses to stress (Hatzenbuehler \& McLaughlin, 2014), or higher and less variable cortisol levels throughout the day (Parra et al., 2016)

\section{(Appendix B).}

There is mixed evidence regarding the exact mechanisms of SGM stressors' impact on the HPA axis. For example, some research indicates that SGM stressors, such as disclosure of SGM identity, may have a more notable impact on HPA axis and cortisol activity than normal 
everyday stressors that are not related to minority identity (DuBois et al., 2017; Parra et al., 2016). At the same time, other findings suggest that greater levels of cultural stigma may lead to greater difficulties with self-regulating in minority individuals, making it more difficult to cope with everyday stressors (Burton et al., 2018).

Unfortunately, the impact of minority stress on the HPA axis -- in addition to its impacts on epigenetic mechanisms -- may result in numerous negative physiological health outcomes. This includes inflammation, immune dysfunction, cardiovascular dysfunction, metabolic dysfunction, and endocrine dysfunction. The clinical implications of these physiological problems can include a wide variety of physical health conditions, ranging from heart disease to a higher risk of viral/bacterial infection (which may explain the higher incidence of respiratory infection) (Flentje et al., 2020).

The impact of minority stress on neuroendocrine function is relatively unsurprising when considering how peer rejection and peer victimization can affect brain activity in the broader population. Even outside of SGM groups, instances of peer victimization and bullying across development can impact HPA axis activity and increase cortisol levels (du Plessis et al., 2019; Knack et al., 2011; Östberg et al., 2018), resulting in poorer physical health outcomes (Knack et al., 2011) and problems with brain development in the ventrolateral prefrontal cortical area (du Pleiss et al., 2019). In addition to peer rejection's role in heightening cortisol levels (Peters et al., 2011), it can also affect a variety of limbic/paralimbic brain areas involved in emotional processing, like the insula (Jankowski et al., 2018; Masten et al., 2009; Masten et al., 2012) and anterior cingulate cortex (ACC) (Masten et al., 2009; Masten et al., 2012). Additionally, peer rejection may also lead to decreased activity in the ventral striatum, a region that can help regulate areas involved in emotional distress (Masten et al., 2009). 
Despite the substantial negative impacts of social stress and SGM stress on physiological, psychological, and physical well-being, there appear to be protective factors associated with social connection, regardless of SGM status. For instance, Masten and colleagues (2012) indicate that, in general, more time spent with friends during adolescence may be related to less activity in the dorsal ACC and anterior insula in later instances of peer rejection -- two brain regions that are otherwise typically active during peer rejection. Furthermore, in another study, prosocial stimuli seemed to heighten ventral striatum activity in adolescents, which was ultimately related to long-term declines in risk-taking behavior (Tezler et al., 2013).

For SGM in particular, feeling connected to the LGBTQ community seems to substantially buffer the negative mental health impacts of minority stress, stigma, discrimination, and interpersonal rejection (Bockting et al., 2013; Ceatha et al., 2019; Fredriksen-Goldsen et al., 2014; Green et al., 2020; Harper et al., 2012; McCormick, 2017; Meyer, 2003; Meyer 2015; Pflum et al., 2015; Russell \& Richards, 2003; Zimmerman et al., 2015). Frost and Meyer (2012) state that connection to the LGBTQ community can satisfy the need to belong to a collective, establish mutually beneficial relationships, and experience emotional connection.

Meanwhile, there is an extensive list of reported benefits for SGM, both tangible and intangible, associated with involvement, consciousness, and connectedness to LGBTQ communities. Intangible benefits may include the improvement of self-esteem (Austin \& Goodman, 2017), self-worth, and self-acceptance (Perrin et al., 2019), the affirmation of SGM identity (Bockting et al., 2013), the promotion of identity pride and resilience (Bockting et al., 2013; Perrin et al., 2019), and networks for social support (Perrin et al., 2019). Feeling connected to the community can also provide validation through others that have gone through similar experiences, in addition to opportunities to bond through hardships and form social support 
groups (Harper et al., 2012). Moreover, some LGBTQ community members report using LGBTQ social support to reframe social values and norms, thereby redefining life goals and measures of success (Meyer, 2015).

Additionally, LGBTQ community connection provides access to tangible resources, social support, exposure to health promoting information and behaviors, and opportunities for activism (Perrin et al., 2019). Tangible resources may include LGBTQ community centers, clinics, support groups, hotlines, and role models. Furthermore, individuals are able to work towards mobilizing SGM rights by bringing together LGBTQ community members for activist efforts (Meyer, 2015). Lastly, taking advantage of community resources allows LGBTQ people to develop "families of choice" in response to family rejection (Fredriksen-Goldsen et al., 2014).

\section{Mechanisms of Resilience \& Community: Activism, Internet and Music}

Activism has been a prominent theme in LGBTQ communities for decades. The most iconic example is the 1969 Stonewall Uprising in New York City, which triggered the momentum for the gay rights movement and annual LGBTQ Pride celebrations (Guarino, 2019; Haber, 2019; Helibroner \& Davis, 2010). Before the Stonewall Uprising, there were very little protections or rights for LGBTQ Americans. LGBTQ individuals were considered deviant and mentally ill, and underwent inhumane treatments like aversive conditioning and lobotomies in order to be "cured" of their condition. Having their identity "outed" could ruin their career, housing, and more. As LGBTQ visibility increased, so did homophobic violence and “gay-bashing.” (Helibroner \& Davis, 2010). Individuals could get arrested for dancing with others of the same sex or cross-dressing (Guarino, 2019), and soon before the Stonewall Uprising began, New York saw as many as 500 people per year arrested for these sort of LGBTQ-related “crimes” (Helibroner \& Davis, 2010). 
Before 1969, one coping method for LGBTQ communities involved the formation of activist gay rights groups like the Mattachine Society and Daughters of Bilitis. Many LGBTQ individuals also gathered in community-specific spaces, such as underground gay bars like the Stonewall Inn (the location of the 1969 uprising) (Helibroner \& Davis, 2010). Eventually, once the New York LGBTQ community had had enough, the unprecedented and spontaneous 1969 Stonewall Uprising provided empowerment -- and even joy -- to the participants. This reported joy was due to the fact that, for the first time, they were not afraid to publicly express themselves (Helibroner \& Davis, 2010)

In the coming months, LGBTQ communities continued practicing resilience and activism. New York community members continued organizing marches. This led to the 1970 Christopher Street Liberation Day: the first anniversary of the Stonewall Uprising, also known as the first Pride celebration (Helibroner \& Davis, 2010). Furthermore, Marsha P. Johnson and Sylvia Rivera -- two community activists and transgender women of color -- formed S.T.A.R. (Street Transvestite Action Revolutionaries) in 1970. This was the first group to fight for transgender rights, while also providing food and shelter to homeless LGBTQ youth in New York City (Guarino, 2019).

According to empirical data, activism (Battle et al., 2017; Harper et al., 2012), movement perspective (Russell \& Richards, 2003), and a desire to be knowledgeable about LGBTQ social issues (Harper et al., 2012) have continued to be important resilience factors for SGM in the following decades. However, LGBTQ communities have also continuously struggled with true inclusivity, and there is still a long way to go. During Christopher Street Liberation Day in 1970, community rights leader Sylvia Rivera spent the day struggling to reach the stage to speak. Once she finally reached the stage, she was booed by white cisgender gay and lesbian people due to 
her demographic as a transgender woman of color. Some say that, during that time, LGB communities viewed transgender people as a "nuisance" and an "embarrassment" (Haber, 2019). Furthermore, an interview with Rivera in 2007 documented her experience with how transgender people of color continued to be dismissed and overlooked throughout the following decades (Rivera, 2007).

Meyer (2015) suggests that, even within the last ten years, not all segments of the LGBTQ community can benefit from community resources equally, and that some subgroups face additional obstacles accessing these resources. LGBTQ BIPOC (Black, Indigenous, and People of Color) comprise one of these less advantaged subgroups, due to experiencing racism in addition to SGM stress. LGBTQ BIPOC often report feeling invisible (Balsam et al., 2011; Frost \& Meyer, 2012), excluded, exoticized (Balsam et al., 2011), marginalized, or less connected to the broader LGBTQ community than white SGM (Frost \& Meyer, 2012). They also report experiences of sexual objectification or rejection on the basis of race (Balsam et al., 2011). Altogether, the obstacles that LGBTQ BIPOC face can limit their ability to identify with the broader community (Meyer, 2015), which is especially problematic when considering how important LGBTQ community connection can be for buffering SGM stress.

LGBTQ BIPOC report daily experiences of microaggressions -- categorized as microassaults, microinvalidations, and microinsults -- that typically come from a place of ignorance, rather than malice. Even though these microaggressions are not always meant with ill intent, their cumulative effects can still lead to poorer mental and physical health outcomes for LGBTQ BIPOC. Other times, racism and racial exclusion may manifest in more blatant forms, including instances of exclusion from LGBTQ events and spaces, and race being mentioned in online dating/sexual ads (i.e., "white people only") (Balsam et al., 2011). In spite of this, one 
study suggests that direct community involvement and activism may serve as a predictor for how connected LGBTQ BIPOC may feel to the broader LGBTQ community (Battle et al., 2017). This seems to reflect the value of activism in SGM communities. Unfortunately, the literature for racism in LGBTQ communities, and LGBTQ BIPOC intersectionality, is comparatively limited, due to several key challenges like regulatory obstacles, lack of funding, and the tense/chaotic political climate in recent years (Hatzenbuehler, 2017).

Although true inclusivity within LGBTQ communities still has a long way to go, some reporters have documented the involvement of LGBTQ communities in the Black Lives Matter (BLM) movement throughout 2020 in a variety of ways (Lang, 2020). These actions may provide hope for the idea that LGBTQ communities are potentially taking the first initial steps towards fostering more inclusive spaces.

The introduction of this paper defined BLM as a movement against racial injustice. Although the movement, and its fight against police brutality, dates back to 2013, the inhumane murder of George Floyd by Minneapolis police officers triggered a significant wave of protests (Burch \& Eligon, 2020; Hill et al., 2020; McCoy, 2020). While the movement gained awareness and the COVID-19 pandemic persisted, LGBTQ communities and Pride organizations worked to provide support for vulnerable LGBTQ individuals, including nightlife professionals who lost their jobs (Schaffer, 2020) and people impacted by systemic racism (Lang, 2020).

LGBTQ organizations from all over the country held rallies and events in support of BLM. The Reclaim Pride Coalition, based in New York City, has a tradition of pushing for representation and safety of community members beyond cisgender white gay males. This includes rallies that push for the recognition of Marsha P. Johnson and Sylvia Rivera, and their 
contributions to the gay rights movement. On June 28th, they hosted the Queer Liberation March for Black Lives and Against Police Brutality (Lang, 2020; Reclaim Pride Coalition, 2020). In order to provide solidarity and push for awareness, over 100 LGBTQ advocacy organizations, including GLAAD and The Trevor Project, signed onto an open letter calling white supremacy "as defining a characteristic of the American experience as those ideals upon which we claim to hold our democracy." The Baltimore Safe Haven held a rally at Baltimore City Hall to protest the murder of Tony McDade, a black transgender man killed by Tallahassee police officers just a few days after Floyd's murder. A Queer Pride raised funds for black-led organizations in Chicago, and on June 20th, Porch Pride (a socially distanced event) raised money for groups like the Black Trans Advocacy Coalition and Homeless Black Trans Women Fund (Lang, 2020).

LGBTQ communities celebrated Transgender Day of Awareness in November by continuing to lift LGBTQ BIPOC voices. For instance, the Queer Resource Center (QRC) at Portland State University honored this season by collaborating with the PSU Pan-African Commons and PSU Queer Students of Color Program, hosting talks such as "Black \& Trans in the PNW" via the Queer Black Liberation Series. They also featured talks by, and visibility of, black transgender activists, writers, and actors such as Dominique Morgan, L'lerrét Jazelle, Marquise Vilsón, and more (Appendix C). Lastly, in their newsletter advertising these events, the QRC attached an Action on Anti-Black Racism Statement. This statement describes the specific steps the QRC planned to take in order to support black community members, and highlights the often overlooked legacy of black transgender women who spearheaded the gay rights movement, such as Marsha P. Johnson and more. As the document states, "Queer and 
transgender rights are inexplicably tied to Black labor and Black liberation” (QRC Leadership Team, 2020).

In 2020, the theme for LGBTQ communities centered on solidarity for BLM. While these were valuable first steps, it is crucial that this advocacy for LGBTQ BIPOC remains -- and strengthens -- over time. Nonetheless, the rallies, events, and actions promoted by SGM communities in 2020 reflects the value of LGBTQ activism during times of crisis.

In addition to activist efforts, LGBTQ communities also utilized internet spaces as a coping method in 2020. A study by Rodriguez-Seijas and colleagues (2020) supported this statement. Their findings indicate that, for quarantined LGBTQ individuals in 2020, engaging in online socialization correlated with reduced rates of depression. This may suggest that internet use provided a mechanism for social connectedness in LGBTQ communities, which in turn buffered against the negative impacts of the COVID-19 pandemic in 2020.

Even before the onset of the pandemic, data has suggested how internet use can provide benefits for LGBTQ youth. For instance, Hillier and colleagues (2012) state that LGB youth utilize the internet differently than heterosexual youth, especially in regards to friendships, relationships, romance, and sexual exploration. Their findings suggest that it may be easier for LGB youth to find LGB peer support from online services compared to their everyday lives. They may also reveal their identity more readily online, since they are less concerned about stigma and judgment online than in everyday life. Additionally, positive mechanisms of online services may include using the internet to progress social change, foster positive identity development (Mehra et al., 2004), encourage activism (Battle et al., 2017), and discover greater access to resources and opportunities (Palmer et al., 2013). Importantly, the use of online peer 
support forums for LGBTQ individuals may even help buffer the relationship between minority stress and suicidal ideation (McCormick, 2017).

At the beginning of the COVID-19 pandemic, The Trevor Project stressed how important it is for LGBTQ youth to maintain pre-existing virtual connections and engage in online activities during social quarantine. They emphasized how LGBTQ youth can utilize online safe spaces to seek affirming relationships (Green et al., 2020). Some of these resources include pre-existing safe spaces like TrevorSpace, Trevor Chat, Trevor Lifeline, and the LGBTQ chat feature of The Tribe Wellness Community (Appendix D).

Ultimately, LGBTQ communities followed The Trevor Project's suggestions during 2020 to counter COVID-19's impacts on social isolation. Communities from all over the world worked together to host a global virtual event called "Global Pride" (Haynes, 2020), and local organizations like Portland Pride hosted a virtual festival which contained a series of inspirational videos, performances, talks, and interviews (Stein, 2020). Additionally, the well-known actor Elliot Page came out about his transgender identity on social media, providing inspiration and encouragement for LGBTQ fans during a particularly trying year (O'Kane, 2020).

Many organizations combined activism and internet spaces in response to the 2020 crises. In addition to the previously discussed TDoR events held by Portland State University's QRC, The Louisville Pride Foundation held a Facebook Fundraiser that donated to The Bail Project \& Social Justice Fund. NY City Pride held a virtual rally hosted by black transgender community members Ashlee Marie Preston (activist) and Brian Michael Smith (actor). Furthermore, NY City Pride's website posted resources and tips for protesters (Lang, 2020). 
Lastly, LGBTQ communities embodied resilience in 2020 through the use of music, which has been shown to provide substantial benefits for social cohesion, stress reduction, mood regulation, and dopamine reward systems. The neuroscience of music is highly complex, integrating many areas of the brain in both hemispheres, limbic networks, auditory and somatosensory cortices, dopamine reward systems, the mirror neuron system, plasticity, and more (Wang \& Angius, 2018). For the purposes of this paper, only the most relevant of these interactions will be discussed.

A variety of sources report that music encourages social cohesion, bonding, and connection (Boer \& Abubakar, 2014; Chanda \& Levitin, 2013; Huron, 2006; Koelsch, 2010; Schäfer et al., 2013). For instance, music may serve to promote group solidarity, altruism, conflict reduction, and interpersonal mood synchronization (Huron, 2006). This may partially be the result of music's ability to promote oxytocin release (Chanda \& Levitin, 2013; Ooishi et al., 2017). Other neurochemicals potentially involved in these social bonding mechanisms may include endorphins, vasopressin, serotonin, and dopamine. Additionally, music can promote co-activation of certain neural networks between individuals, which may be the foundation for a "self-other merging" phenomenon in the presence of music (Tarr et al., 2014). It also seems that, when people synchronize their movements in the presence of music (i.e., through dance), this can promote cooperation, affiliation, connectedness, likability, and social bonding (Stupacher et al., 2017).

Music plays a role in mood regulation (Chanda \& Levitin, 2013; Schäfer et al., 2013), especially via the promotion of positive emotions, alleviation of stress (Gangrade, 2012), and reduction or elimination of bad moods (Huron, 2006). Crucially, from a physiological perspective, music regulates the HPA axis and decreases cortisol activity (Chanda \& Levitin, 
2013; Gangrade, 2012; Grebosz-Haring \& Thun-Hohenstein, 2018; Ooishi et al., 2017; Thoma et al., 2013). Music also may inhibit the increase of cortisol levels immediately following a stressful event (Khalfa et al., 2013). This implicates music as a powerful coping tool when considering the previously discussed relationship between SGM stress and the HPA axis. In fact, Gangrade (2012) asserts that music's regulatory effects can help manage stress and stress-related health issues, including cerebrovascular disease and immune dysfunction, in addition to promoting learning and neurogenesis.

Furthermore, music extensively promotes dopamine reward system activity. For instance, listening to pleasurable music can lead to specifically distinct dopamine release in the striatal system. Within the dorsal striatum, the caudate is typically involved with musical anticipation (Salimpoor et al., 2011), while the ventral striatum's nucleus accumbens is strongly implicated during emotional responses to music (Chanda \& Levitin, 2013; Menon \& Levitin, 2005; Mueller et al., 2015; Salimpoor et al., 2011). An older study by Menon and Levitin (2005) portrayed extensive connectivity between the nucleus accumbens and the anterior insula while listening to music. Furthermore, Chanda and Levitin (2013) emphasize the importance of the anterior insula and anterior cingulate cortex in reward and reinforcement processes. In this context, the relationship between music listening and the aforementioned structures -- specifically, the ventral striatum, insula, and anterior cingulate cortex -- is particularly noteworthy. This is because, as the paper outlined earlier, these regions are also implicated in peer rejection, prosocial interactions, and risk-taking behavior. As a result, these structures provide additional examples beyond the HPA axis for the neuroscientific parallels between music and social behavior.

Evolutionary psychology suggests that music plays a fundamental role in satisfying the human need for social connection and bonding (Huron, 2006; Schäfer et al., 2013; Tarr et al., 
2014). Additionally, Ceatha and colleagues (2019) indicate that "interest groups," such as creative groups, could be an effective strategy for fostering connectedness among LGBTQ individuals. The musical events and festivals held by LGBTQ communities in 2020 served to bear out these theories and data. Ultimately, LGBTQ communities fostered resilience and connection by discovering ways to combine music, internet, and activism, especially during Pride season.

For instance, Wynwood Pride hosted DJs and performers on Twitch, and donated the money they raised to Color of Change, Equal Justice Initiative, and Impact Justice (Lang, 2020). Earlier in the year, on April 23rd, the Stonewall Gives Back Initiative threw a livestream musical fundraiser to provide emergency assistance for LGBTQ individuals in the nightlife industry (Schaffer, 2020). Both this event and Global Pride featured a multitude of musical performers (Taylor, 2020). Small-scale communities like the local Sacramento music scene (among many others) followed suit by hosting events like "916 Pride Show 4," a local music festival featuring LGBTQ Sacramento musicians, co-hosted by the author of this paper and 916 Growth Gigs (Appendix E). Although the donations were meant to be split equally between the performers and NorCal Resist's Activist Bail and ICE Bond Fund, the majority of the performers donated their share to NorCal Resist.

\section{Limitations and Implications}

The constructs covered here are broad and complex, so this paper only scratches the surface of these ideas. Additionally, the COVID-19 pandemic extends beyond 2020, and the systemic social issues addressed long precede 2020. However, the examples discussed portray how LGBTQ communities adapted to the simultaneous challenges seen in 2020. 
As Meyer (2015) discusses, the experiences of LGBTQ individuals are dramatically heterogeneous due to a variety of factors. This includes whether or not the individual must face racism, classism, sexism, biphobia, transphobia, or any other type of exclusion from the broader community. Additionally, the literature on transgender minority stress is lacking in comparison to LGB research, and intersectionality research needs to be expanded. Unfortunately, it has been difficult to implement these goals due to a variety of systemic obstacles (Hatzenubuehler, 2017). The paper at hand is not an empirical study, and does not aim to generalize the experience of all LGBTQ individuals in 2020. However, the ideas and examples discussed may lay the groundwork for potential areas of research.

One future avenue of research may include qualitative studies investigating SGM resilience in response to 2020 crises, on both an individual and community level. This may be accompanied by expanded bodies of literature documenting the impact of the COVID-19 pandemic on LGBTQ communities. Transgender minority stress, in addition to LGBTQ/BIPOC intersectionality, must be studied in greater detail, including the existence of transphobia amongst LGB individuals, and racism within LGBTQ communities. Additional research implications could include the potentially protective role of music intervention for LGBTQ individuals and communities. Lastly, it may be helpful for literature to expand the research on the specific neuroscientific and neurohormonal mechanisms of SGM stress.

In addition, this paper provides multiple social implications. It is crucial for LGBTQ communities to maintain and strengthen the core value of connection through activism. Activistic measures must be taken to fight for black lives and transgender rights, and to provide solidarity. During times of crisis (like the ongoing COVID-19 pandemic), it is necessary for resources, protections, and support to be available for vulnerable community members. This 
includes multiple minority individuals, LGBTQ people who lack housing and healthcare, and isolated LGBTQ youth trapped in abusive, anti-SGM environments. Although full inclusion within LGBTQ communities still has a long way to go, the examples discussed here provide hope for the resilience and solidarity that SGM communities are capable of embodying. 


\section{Works Cited}

Austin, A., \& Goodman, R. (2017). The impact of social connectedness and internalized transphobic stigma on self-esteem among transgender and gender non-conforming adults. Journal of Homosexuality, 64(6), 825-841. https://doi.org/10.1080/00918369.2016.1236587

Balsam, K., Molina, Y., Beadnell, B., Simoni, J., \& Walters, K. (2011). Measuring multiple minority stress: The LGBT People of Color Microaggressions Scale. Cultural Diversity and Ethnic Minority Psychology, 17, 163-174. https://doi.org/10.1037/a0023244

Battle, J., Peterson, R. B., Lucas, N., \& Applewhite, S. (2017). Their own received them not: Black LGBT feelings of connectedness. Journal of Black Sexuality and Relationships, 4(2), 45-72. https://doi.org/10.1353/bsr.2017.0027

Biskupic, J. (2020). With court in flux, Thomas and Alito attack same-sex marriage ruling. CNN. https://www.cnn.com/2020/10/05/politics/thomas-alito-obergefell-same-sex-marriage-an $\underline{\text { lysis/index.html }}$

Bockting, W. O., Miner, M. H., Swinburne Romine, R. E., Hamilton, A., \& Coleman, E. (2013). Stigma, mental health, and resilience in an online sample of the US transgender population. American Journal of Public Health, 103(5), 943-951. https://doi.org/10.2105/AJPH.2013.301241

Boer, D., \& Abubakar, A. (2014). Music listening in families and across peer groups; benefits for young peoples' social cohesion and emotional well-being across four cultures. Frontiers in Psychology, 5: 392. https://doi.org/10.3389/fpsyg.2014.00392

Bogart, L., Revenson, T., Whitfield, K. E., \& France, C. R. (2013). Introduction to the special section on lesbian, gay, bisexual, and transgender (LGBT) health disparities: Where we 
are and where we're going. Annals of Behavioral Medicine, 47(1), 1-4. https://doi.org/10.1007/s12160-013-9574-7

Burch, A. D. S., \& Eligon, J. (2020). Bystander videos of George Floyd and others are policing the police. The New York Times. https://www.nytimes.com/2020/05/26/us/george-floyd-minneapolis-police.html

Burton, C. L., Wang, K., \& Pachankis, J. E. (2018). Does getting stigma under the skin make it thinner? Emotion regulation as a stress-contingent mediator of stigma and mental health. Clinical Psychological Science, 6(4), 590-600. https://doi.org/10.1177/2167702618755321

Cameron, C. (2020). HUD rule would dismantle protections for homeless transgender people. The New York Times. https://www.nytimes.com/2020/07/01/us/politics/hud-transgender.html

Casey, L. S., Reisner, S. L., Findling, M. G., Blendon, R. J., Benson, J. M., Sayde, J. M., \& Miller, C. (2019). Discrimination in the United States: Experiences of lesbian, gay, bisexual, transgender and queer Americans. Health Services Research, 54(S2), 1454-1466. https://doi.org/10.1111/1475-6773.13229

Ceatha, N., Mayock, P., Campbell, J., Noone, C., \& Browne, K. (2019). The power of recognition: A qualitative study of social connectedness and well-being through LGBT sporting, creative and social groups in Ireland. International Journal of Environmental Research and Public Health, 16(19): 3636. https://doi.org/10.3390/ijerph16193636

Chanda, M. L., \& Levitin, D. J. (2013). The neurochemistry of music. Trends in Cognitive Sciences, 17(4), 179-193. https://doi.org/10.1016/j/tics.2013.02.007 
Chang, C. J., Fehling, K. B., \& Selby, E. A. (2020). Sexual minority status and psychological risk for suicide attempt: a serial multiple mediation model of social support and emotion regulation. Frontiers in Psychiatry, 11: 385. https://doi.org/10.3389/fpsyt.2020.00385

Cochran, S. D., \& Mays, V. M. (2007). Physical health complaints among lesbians, gay men, and bisexual and homosexually experienced heterosexual individuals: results from the California Quality of Life Survey. American Journal of Public Health, 97(11), 2048-2055. https://doi.org/10.2105/AJPH.2006.087254

Cochran, S. D., Sullivan, J. G., \& Mays, V. M. (2003). Prevalence of mental disorders, psychological distress, and mental health services use among lesbian, gay, and bisexual adults in the United States. Journal of Consulting and Clinical Psychology, 71(1), 53-61. https://doi.org/10.1037/0022-006X.71.1.53

DuBois, Z. L., Powers, S., Everett, B. G., \& Juster, R.-P. (2017). Stigma and diurnal cortisol among transitioning transgender men. Psychoneuroendocrinology, 82, 59-66. https://doi.org/10.1016/i.psyneuen.2017.05.008

du Pleiss, M. R., Smeekens, S., Cillessen, A. H. N., Whittle, S., \& Güroğlu, B. (2019). Bullying the brain? Longitudinal links between childhood peer victimization, cortisol, and adolescent brain structure. Frontiers in Psychology, 9: 2706. https://doi.org/10.3389/fpsyg.2018.02706

Flentje, A., Heck, N. C., Brennan, J. M., \& Meyer, I. H. (2020). The relationship between minority stress and biological outcomes: a systematic review. Journal of Behavioral Medicine, 43, 673-694. https://doi.org/10.1007/s10865-019-00120-6

Fredriksen-Goldsen, K. I., Simoni, J. M., Kim, H-J., Lehavot, K., Walters, K. L., Yang, J., \& Hoy-Ellis, C. P. (2014). The Health Equity Promotion Model: Reconceptualization of 
Lesbian, Gay, Bisexual, and Transgender (LGBT) Health Disparities. American Journal of Orthopsychiatry, 84(6), 653-663. https://doi.org/10.1037/ort0000030

Frost, D. M. \& Fingerhut, A. (2016). Daily exposure to negative campaign messages decreases same-sex couples' psychological and relational well-being. Group Processes and Intergroup Relations, 19(4), 477-492. https://doi.org/10.1177/1368430216642028

Frost, D. M., \& Meyer, I. H. (2012). Measuring community connectedness across diverse sexual minority populations. The Journal of Sex Research, 49(1), 36-49. https://doi.org/10.1080/00224499.2011.565427

Gangrade, A. (2012). The effect of music on the production of neurotransmitters, hormones, cytokines, and peptides: A review. Music and Medicine, 4(1), 40-43. https://doi.org/10.1177/1943862111415117

Gonzales, G., \& Ehrenfeld, J. M. (2018). The association between state policy environments and self-rated health disparities for sexual minorities in the United States. International Journal of Environmental Research and Public Health, 15(6): 1136. https://doi.org/10.3390/ijerph15061136

Gonzalez, K. A., Ramirez, J. L., \& Galupo, M. P. (2018). Increase in LGBTQ minority stress following the 2016 US presidential election. Journal of GLBT Family Studies, 14, 130-151. https://doi.org/10.1080/1550428X.2017.1420849

Grebosz-Haring, K., \& Thun-Hohenstein, L. (2018). Effects of group singing versus group music listening on hospitalized children and adolescents with mental disorders: A pilot study. Heliyon, 4(12), 1-28. https://doi.org/10.1016/i.heliyon.2018.e01014

Green, A. E., Price-Freeny, M., \& Dorison, S. H. (2020). Implications of COVID-19 for LGBTQ youth mental health and suicide prevention. The Trevor Project. 
https://www.thetrevorproject.org/wp-content/uploads/2020/04/Implications-of-COVID9-for-LGBTQ-Youth-Mental-Health-and-Suicide-Prevention.pdf

Guarino, E. (2019). Stonewall at 50 [Motion Picture]. United States of America: New York University. https://www.nyu.edu/about/university-initiatives/nyu-celebrates-stonewall-at-50/stonewa 1-at-50-documentary.html

Haber, R. (2019). Stonewall forever - A documentary about the past, present and future of pride [Motion Picture]. United States of America: NYC's LGBT Community Center. https://www.youtube.com/watch?v=GjRv7dJTync\&ab channel=LGBTCenterNYC

Harper, G. W., Brodsky, A., \& Bruce, D. (2012). What's good about being gay? Perspectives from youth. Journal of LGBT Youth, 9(1), 22-41. https://doi.org/10.1080/19361653.2012.628230

Hatzenbuehler, M. L. (2009). How does sexual minority stigma "get under the skin?” A psychological mediation framework. Psychological Bulletin, 135(5), 707-730. https://doi.org/10.1037/a0016441

Hatzenbuehler, M. L. (2017). Advancing research on structural stigma and sexual orientation disparities in mental health among youth. Journal of Clinical Child \& Adolescent Psychology, 46(3), 463-475. https://doi.org/10.1080/15374416.2016.1247360

Hatzenbuehler, M. L., \& McLaughlin, K. A. (2014). Structural stigma and hypothalamic-pituitary-adrenocortical axis reactivity in lesbian, gay and bisexual young adults. Annals of Behavioral Medicine, 47(1), 39-47. https://doi.org/10.1007/s12160-013-9556-9

Hatzenbuehler, M. L., McLaughlin, K. A., Keyes, K. M., \& Hasin, D. S. (2010). The impact of 
institutional discrimination on psychiatric disorders in lesbian, gay, and bisexual populations: A prospective study. American Journal of Public Health, 100(3), 452-459. https://doi.org/10.2105/AJPH.2009.168815

Haynes, S. (2020). Challenged by COVID-19, LGBTQ Communities worldwide plan digital pride celebrations. TIME. https://time.com/5814554/coronavirus-lgbtq-community-pride/

Helibroner, D., \& Davis, K. (2010). Stonewall uprising [Motion Picture]. United States of America.

Hill, E., Tiefenthäler, A., Triebert, C., Jordan, D., Wilis, H., \& Stein, R. (2020). How George Floyd was killed in police custody. The New York Times. https://www.nytimes.com/2020/05/31/us/george-floyd-investigation.html

Hillier, L., Mitchell, K. J., \& Ybarra, M. L. (2012). The internet as a safety net: Findings from a series of online focus groups with LGB and non-LGB young people in the United States. Journal of LGBT Youth, 9: 225-246. https://doi.org/10.1080/19361653.2012.684642

Hirsch, J. K., Kaniuka, A., Brooks, B., Hirsch, K. K., Cohn, T. J., \& Williams, S. L. (2017). Postelection distress and resiliency in LGBT communities: An overview of real data, not alternative facts. Society for the Psychology of Sexual Orientation and Gender Diversity. APA Divisions.

https://www.apadivisions.org/division-44/publications/newsletters/division/2017/03/post $\underline{\text { lection-distress }}$

Hughto, J. M. W., Reisner, S. L., \& Pachankis, J. E. (2015). Transgender stigma and health: A critical review of stigma determinants, mechanisms, and interventions. Social Science \& Medicine, 147, 222-231. https://doi.org/10.1016/j.socscimed.2015.11.010

Human Rights Campaign Foundation (2017). Post-election survey of youth. Human Rights 


\section{Campaign.}

\section{https://assets2.hrc.org/files/assets/resources/HRC PostElectionSurveyofYouth.pdf}

Huron, D (2006). Is music an evolutionary adaptation? Annals New York Academy of Sciences, 930(1), 43-61. https://doi.org/10.1111/j.1749-6632.2001.tb05724.x.

Jankowski, K. F., Batres, J., Scott, H., Smyda, G., Pfeifer, J. H., \& Quevedo, K. (2018). Feeling left out: depressed adolescents may atypically recruit emotional salience and regulation networks during social exclusion. Social Cognitive and Affective Neuroscience, 13(8), 863-876. https://doi.org/10.1093/scan/nsy055

Johns, M. M., Lowry, R., Andrzejewski, J., Barrios, L. C., Demissie, Z., McManus, T., Rasberry, C. N., Robin, L., \& Underwood J. M. (2019). Transgender identity and experiences of violence victimization, substance use, suicide risk, and sexual risk behaviors among high school students - 19 states and large urban school districts, 2017. Morbidity and Mortality Weekly Report, 68(3), 67-71. https://doi.org/10.15585/mmwr.mm6803a3

Kiekens, W., la Roi, C., Bos, H. M. W., Kretschner, T., van Bergen, D. D., \& Veenstra, R. (2020). Explaining health disparities between heterosexual and LGB adolescents by integrating the minority stress and psychological mediation frameworks: Findings from the TRAILS study. Journal of Youth and Adolescence, 49, 1767-1782. https://doi.org/10.1007/s10964-020-01206-0

Khalfa, S., Bella, S. D., Roy, M., Peretz, I., \& Lupien, S. J. (2003). Effects of relaxing music on salivary cortisol level after psychological stress. Annals of the New York Academy of Sciences, 999: 374-376. https://doi.org/10.1196/annals.1284.045

Knack, J. M., Jensen-Campbell, L. A., \& Blaum, A. (2011). Worse than sticks and stones? Bullying is associated with altered HPA axis functioning and poorer health. Brain and 
Cognition, 77(2), 183-190. https://doi.org/10.1016/j.bandc.2011.06.011

Koelsch, S. (2010). Towards a neural basis of music-evoked emotions. Trends in Cognitive Sciences, 14(3), 131-137. https://doi.org/10.1016/j.tics.2010.01.002

Kuhr, E. (2020). Coronavirus pandemic a perfect storm for LGBTQ homeless youth. NBC News. https://www.nbcnews.com/feature/nbc-out/coronavirus-pandemic-perfect-storm-lgbtq-h meless-youth-n1176206

Lang, N. (2020). Queer Pride is going back to its protest roots. Rollingstone. https://www.rollingstone.com/culture/culture-features/lgbtq-pride-protest-black-lives-ma $\underline{\text { ter-1011734/ }}$

Masten, C. L., Eisenberger, N. I., Borofsky, L. A., Pfeifer, J. H., McNealy, K., Mazziotta, J. C., \& Dapretto, M. (2009). Neural correlates of social exclusion during adolescence: understanding the distress of peer rejection. Social Cognitive and Affective Neuroscience, 4(2), 143-157. https://doi.org/10.1093/scan/nsp007

Masten, C. L., Telzer, E. H., Fuligni, A. J., Lieberman, M. D., Eisenberger, N. I. (2012). Time spent with friends in adolescence relates to less neural sensitivity to later peer rejection. Social Cognitive and Affective Neuroscience, 7(1), 106-114. https://doi.org/10.1093/scan/nsq098

McCormick, K. (2017). Peer-to-peer support responses to LGBT suicidal ideations in an online community [Master's thesis]. West Virginia University. https://researchrepository.wvu.edu/cgi/viewcontent.cgi? article $=7234 \&$ context $=$ etd

McCoy, H. (2020). Black Lives Matter, and yes, you are racist: The parallelism of the twentieth and twenty-first centuries. Child and Adolescent Social Work Journal, 37, 463-475. https://doi.org/10.1007/s10560-020-00690-4 
Medley, G., Lipari, R. N., \& Bose, J. (2016). Sexual orientation and estimates of adult substance use and mental health: Results from the 2015 National Survey on Drug Use and Health. SAMHSA.

https://www.rollingstone.com/culturehttps:/www.samhsa.gov/data/sites/default/files/NS UH-SexualOrientation-2015/NSDUH-SexualOrientation-2015/NSDUH-SexualOrientati $\underline{\text { n-2015.htm/culture-features/lgbtq-pride-protest-black-lives-matter-1011734/ }}$

Mehra, B., Merkel, C., \& Bishop, A. P. (2004). The internet for empowerment of minority and marginalized users. New Media and Society, 6(6), 781-802. https://doi.org/10.1177/146144804047513

Menon, V., \& Levitin, D. J. (2005). The rewards of music listening: response and physiological connectivity of the mesolimbic system. NeuroImage, 28(1), 175-184. https://doi.org/10.1016/i.neuroimage.2005.05.053

Meyer, I. H. (2003). Prejudice, social stress, and mental health in lesbian, gay, and bisexual populations: Conceptual issues and research evidence. Psychological Bulletin, 129(5), 674-697. https://doi.org/10.1037/0033-2909.129.5.674

Meyer, I. H. (2015). Resilience in the study of minority stress and health of sexual and gender minorities. Psychology of Sexual Orientation and Gender Diversity, 2(3), 209-213. https://doi.org/10.1037/sgd0000132

Mueller, K., Fritz, T., Mildner, T., Richter, M., Schulze, K., Lepsien, J., Schroeter, M. L., \& Moller, H. E. (2015). Investigating the dynamics of the brain response to music: a central role of the ventral striatum/nucleus accumbens. NeuroImage, 116: 68-79. https://doi.org/10.1016/j.neuroimage.2015.05.006

National Center for Health Statistics, \& Centers for Disease Control and Prevention [CDC]. 
Provisional death counts for Coronavirus Disease 2019 (COVID-19). CDC. Retrieved 2021, from https://www.cdc.gov/nchs/nvss/vsrr/covid19/index.htm

Newcomb, M. E., Hill, R., Buehler, K., Ryan, D. T., Whitton, S. W., \& Mustanski, B. (2020). High burden of mental health problems, substance use, violence, and related psychosocial factors in transgender, non-binary, and gender diverse youth and young adults. Archives of Sexual Behavior, 49(2), 645-659. https://doi.org/10.1007/s10508-019-01533-9

O’Kane, C. (2020). "Powerful and inspiring”: Elliot Page receives support and gratitude on social media after announcing he's trans. CBS News.

https://www.cbsnews.com/news/elliot-page-transgender-social-media-support/

Ooishi, Y., Mukai, H., Watanabe, K., Kawato, S., \& Kashino, M. (2017). Increase in salivary oxytocin and decrease in salivary cortisol after listening to relaxing slow-tempo and exciting fast-tempo music. PLoS ONE, 12(12): e0189075.

\section{https://doi.org/10.1371/journal.pone.0189075}

Östberg, V., Låftman, S. B., Modin, B., \& Lindfors, P. (2018). Bullying as a stressor in mid-adolescent girls and boys-associations with perceived stress, recurrent pain, and salivary cortisol. International Journal of Environmental Research and Public Health, 15(2): 364. https://doi.org/10.3390/ijerph15020364

Palmer, N. A., Kosciw, J. G., Greytak, E. A., Ybarra, M. L., Korchmaros, J., \& Mitchell, K. J. (2013). Out Online: The experiences of lesbian, gay, bisexual and transgender youth on the internet. GLSEN. https://www.glsen.org/news/out-online-experiences-lgbt-youth-internet

Parra, L. A., \& Hastings, P. D. (2018). Integrating the neurobiology of minority stress with an intersectionality framework for LGBTQ-Latinx populations. Envisioning the Integration 
of an Intersectional Lens in Developmental Science, 2018(161), 91-108. https://doi.org/10.1002/cad.20244

Parra, L. A., Benibgui, M., Helm, J. L., \& Hastings, P. D. (2016). Minority stress predicts depression in lesbian, gay, and bisexual emerging adults via elevated dirunal cortisol. Emerging Adulthood, 4(5), 1-8. https://doi.org/10.1177/2167696815626822

Perrin, P. B., Sutter, M. E., Trujillo, M. A., Henry, R. S., \& Pugh, M. Jr. (2019). The minority strengths model: Development and initial path analytic validation in racially/ethnically diverse LGBTQ individuals. Journal of Clinical Psychology, 76(1), 118-136. https://doi.org/10.1002/jclp.22850

Peters, E., Riksen-Walraven, M. J., Cillessen, A. H. N., \& de Weerth, C. (2011). Peer rejection and HPA activity in middle childhood: friendship makes a difference. Child Development, 82(6), 1906-1920. https://doi.org/10.1111/i.1467-8624.2011.01647.x

Pflum, S., Testa, R., Balsam, K., Goldblum, P., \& Bongar, B. (2015). Social support, trans community connectedness, and mental health symptoms among transgender and gender nonconforming adults. Psychology of sexual orientation and gender diversity, 2(3), 281-286. https://doi.org/10.1037/sgd0000122

Pilkington, E. (2019). Stonewall at 50: The riot that changed America's gay rights movement forever. The Guardian. https://www.theguardian.com/lifeandstyle/2019/jun/19/stonewall-50th-anniversary-night that-unleashed-gay-liberation

QRC Leadership Team (2020). Action on anti-black racism statement. https://docs.google.com/document/d/1bLZ83JAqdjHR 7xQ-zvFw-CP7CG-8r0Vr6KQA $\underline{\mathrm{n} \text { 458/edit }}$ 
Reclaim Pride Coalition. The 2020 Queer Liberation March. Reclaim Pride Coalition NYC. https://reclaimpridenyc.org/2020-march

Rivera, S. (2007). Sylvia Rivera's talk at LGMNY, June 2001 Lesbian and Gay Community Services Center, New York City. CENTRO: Journal of the Center for Puerto Rican Studies, 19(1), 116-123. file://D:/Downloads/37719106.pdf

Rodriguez-Seijas, C., Fields, E. C., Bottary, R., Kark, S. M., Goldstein, M. R., Kensinger, E. A., Payne, J. S., \& Cunningham, T. J. (2020). Comparing the impact of COVID-19-related social distancing on mood and psychiatric indicators in sexual and gender minority (SGM) and non-SGM individuals. Frontiers in Psychiatry, 11: 590318. https://doi.org/10.3389/fpsyt.2020.590318

Russell, G., \& Richards, J. A. (2003). Stressor and resilience factors for lesbians, gay men, and bisexuals confronting antigay politics. American Journal of Community Psychology, 31(3;4), 313-328. https://doi.org/10.1023/a:1023919022811

Salimpoor, V., Benovoy, M., Larcher, K., Dagher, A., \& Zatorre, R. (2011). Anatomically distinct dopamine release during anticipation and experience of peak emotion to music. Nature Neuroscience, 14(2), 257-262. https://doi.org/10.1038/nn.2726

Santora, M., \& Wolfe, L. (2021). Covid death toll over 2 million worldwide. NY Times. https://www.nytimes.com/2021/01/15/world/covid-death-news.html

Sauer, K. S., Jungmann, S. M., \& Witthöft, M. (2020). Emotional and behavioral consequences of the COVID-19 pandemic: The role of health anxiety, intolerance of uncertainty, and distress (int)tolerance. International Journal of Environmental Research and Public Health, 17: 7241. https://doi.org/10.3390/ijerph17197241

Schäfer, T., Sedlmeier, P., Städtler, C., \& Huron, D. (2013). The psychological functions of 
music listening. Frontiers in Psychology, 4: 511.

https://doi.org/10.3389/fpsyg.2013.00511

Schaffer, C. (2020). Cyndi Lauper, Troye Sivan, and others to appear in LGBTQ livestream for COVID-19 relief. RollingStone.

https://www.rollingstone.com/music/music-news/stonewall-lgbtq-livestream-covid-19-9 $\underline{6975 /}$

Simmons-Duffin, S. (2020). Transgender health protections reversed by Trump administration. NPR.

https://www.npr.org/sections/health-shots/2020/06/12/868073068/transgender-health-pro ections-reversed-by-trump-administration

Santos, T., Mahowald, L., \& Gruberg, S. (2020). The Trump administration's latest attack on transgender people facing homelessness. Center for American Progress. https://www.americanprogress.org/issues/lgbtq-rights/reports/2020/09/03/490004/trump$\underline{\text { dministrations-latest-attack-transgender-people-facing-homelessness/ }}$

Stein, R. (2020). Portland Pride 2020 goes virtual to celebrate community, inclusion during coronavirus pandemic. Oregon Live. https://www.oregonlive.com/events/2020/06/portland-pride-2020-goes-virtual-to-celebra $\underline{\text { e-community-inclusion-during-coronavirus-pandemic.html }}$

Stupacher, J., Maes, P-J., Witte, M., \& Wood, G. (2017). Music strengthens prosocial effects of interpersonal synchronization - if you move in time with the beat. Journal of 
Experimental Social Psychology, 72, 39-44. https://doi.org/10.1016/j.jesp.2017.04.007

Tarr, B., Launay, J., \& Dunbar, R. I. M. (2014). Music and social bonding: "self other” merging and neurohormonal mechanisms. Frontiers in Psychology, 5: 1096.

https://doi.org/10.3389/fpsyg.2014.01096

Taylor, D. B. (2020). World leaders, pop stars and drag queens to headline livestream for gay pride. The New York Times. https://www.nytimes.com/2020/05/30/us/global-pride-day-coronavirus.html

Tezler, E. H., Fuligni, A. J., Lieberman, M. D., \& Galván, A. (2013). Ventral striatum activation to prosocial rewards predicts longitudinal declines in adolescent risk taking. Developmental Cognitive Neuroscience, 3, 45-52. https://doi.org/10.1016/j.dcn.2012.08.004

Thoma, M. V., La Marca, R., Bronnimann, R., Finkel, L., Ehlert, U., \& Nater, U. M. (2013). The effect of music on the human stress response. PLoS ONE, 8(8): e70156. https://doi.org/10.1371/journal.pone.0070156

Wang, S., \& Angius, M. (2018). The neuroscience of music; a review and summary. Psychiatria Danubina, 30(S7), 588-594. http://www.psychiatria-danubina.com/UserDocsImages/pdf/dnb vol30 noSuppl\%207/d b_vol30 noSuppl $\% 207$ 588.pdf

Woolf, S. H., Chapman, D. A., \& Lee, J. H. (2020). COVID-19 as the leading cause of death in the United States. JAMA, 325(2), 123-124. https://doi.org/10.1001/jama.2020.24865 
Zimmerman, L., Darnell, D. A., Rhew, I. C., Lee, C. M., \& Kaysen, D. (2015). Resilience in community: A social ecological development model for young adult sexual minority women. American Journal of Community Psychology, 55(0), 179-190.

https://doi.org/10.1007/s10464-015-9702-6 
Appendix A

HPA Axis

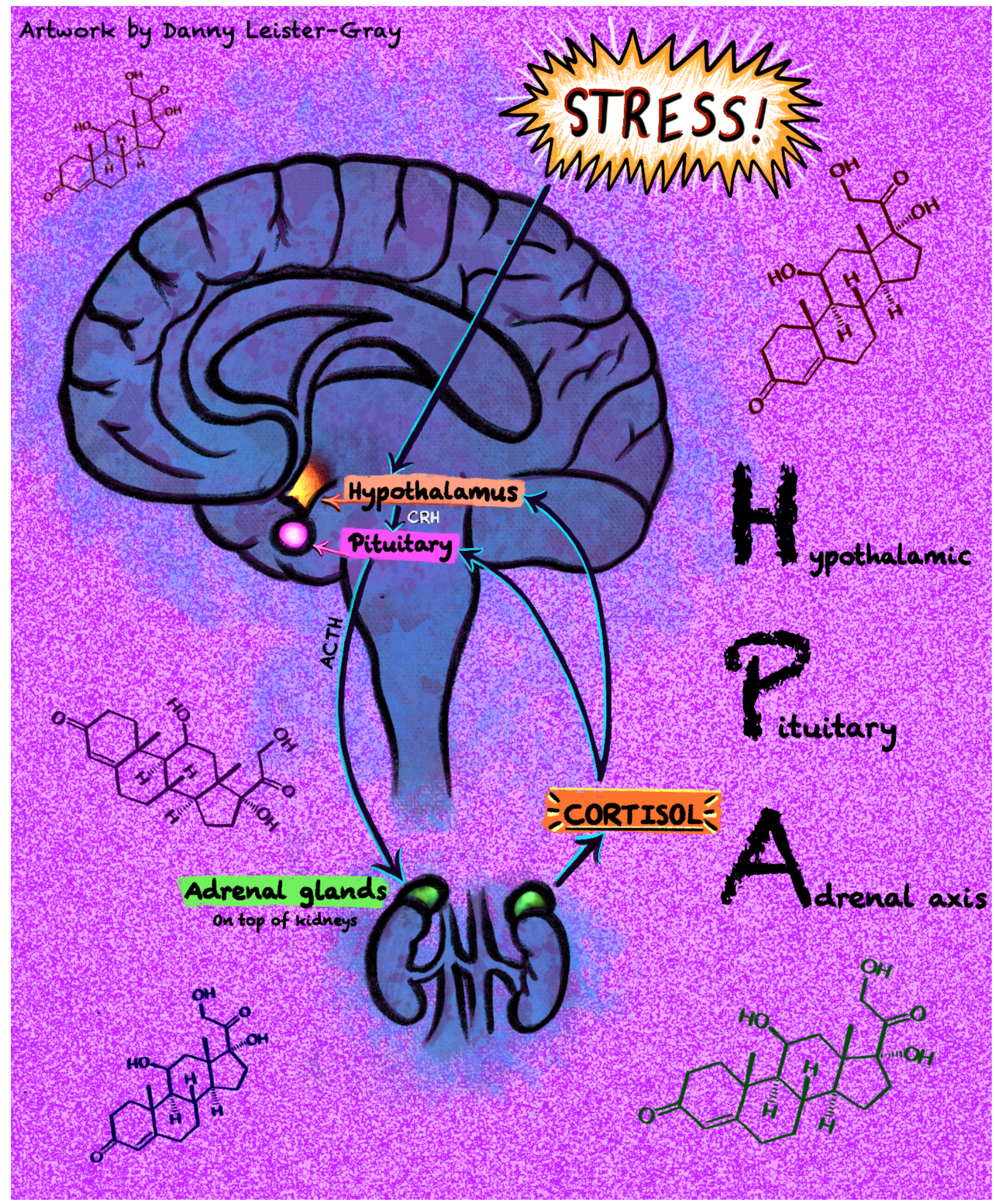




\section{Appendix B}

\section{Cortisol Activity}

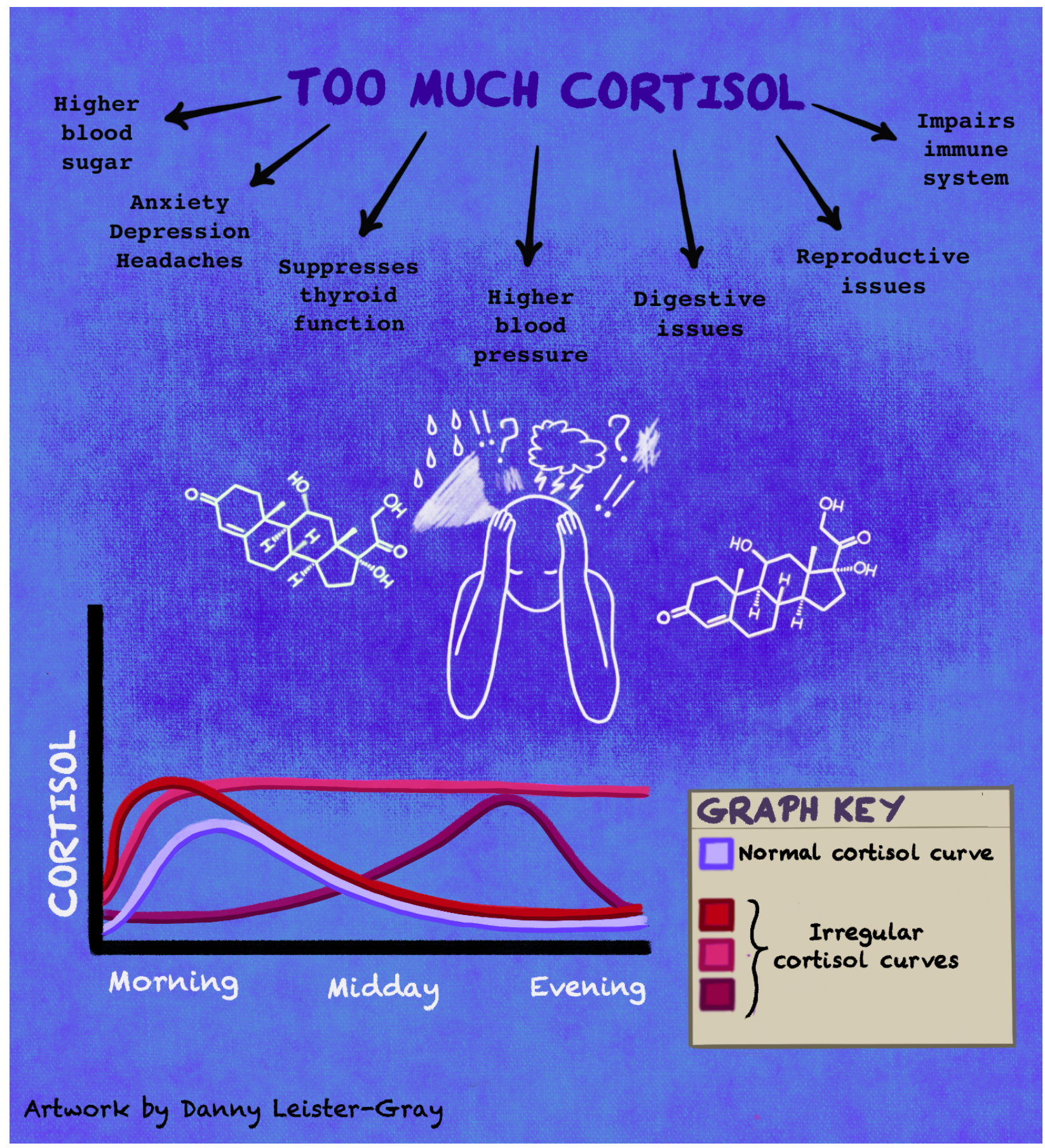


Appendix C

Portland State University TACC \& TEMPRR Events, Featuring...

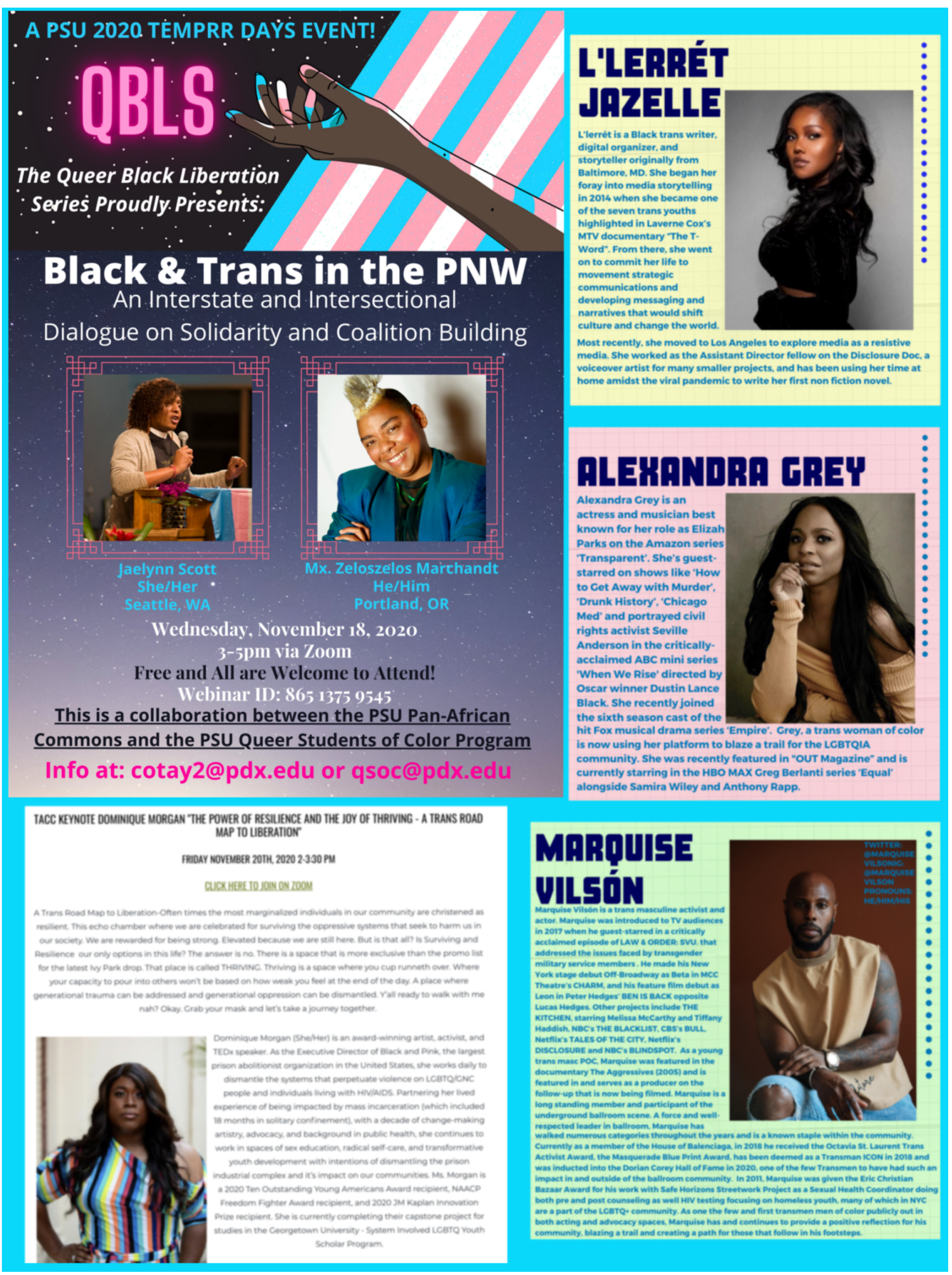




\section{Appendix D}

\section{Pride Show 4 Flyer}

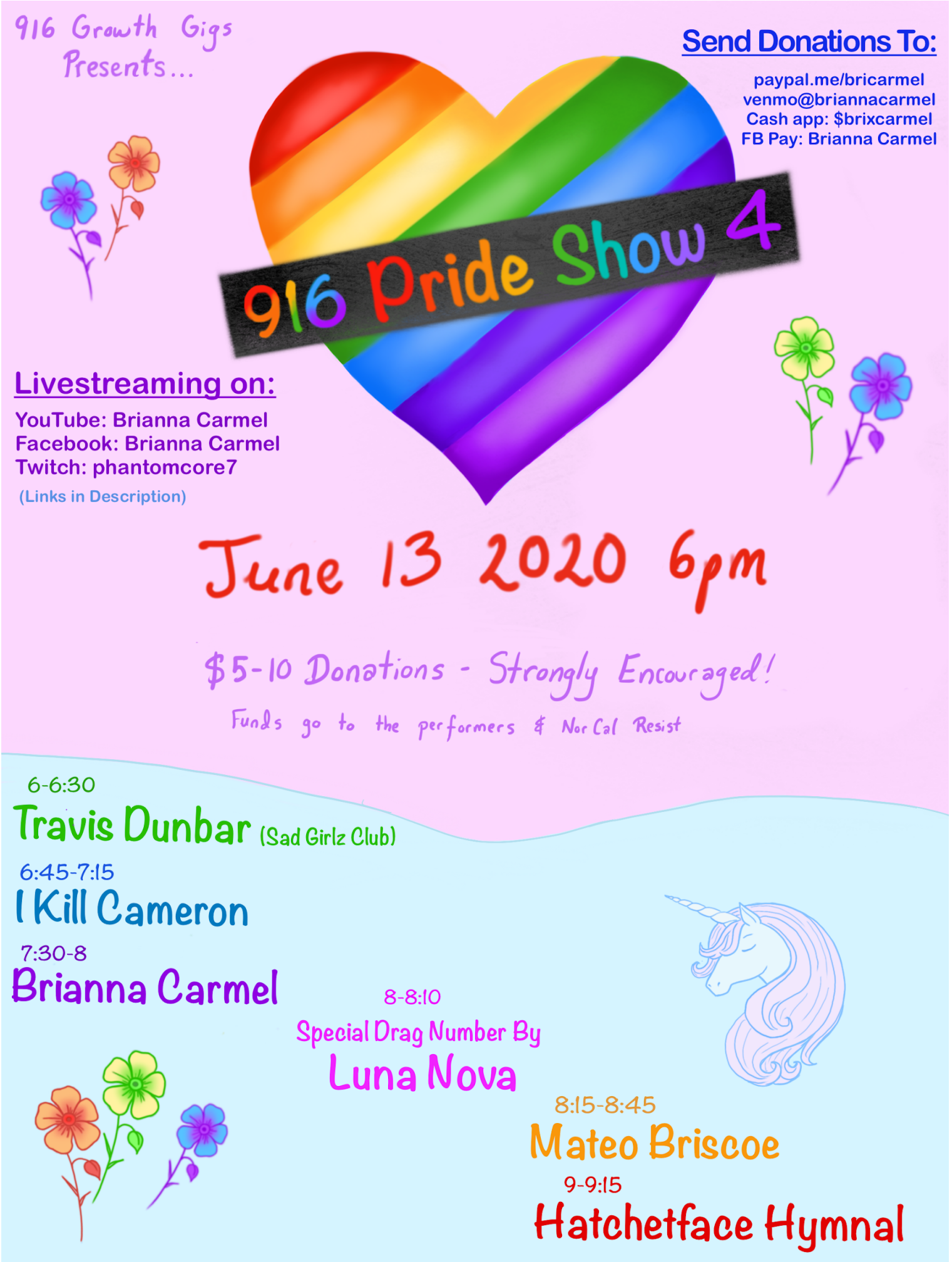




\section{Appendix E}

For LGBTQ

\section{Resources}

\begin{tabular}{|l|l|}
\hline $\begin{array}{l}\text { Sexual and Gender Minority Youth Resource } \\
\text { Center (SMYRC) - Portland }\end{array}$ & $\begin{array}{l}\text { The Gay, Lesbian. Bisexual and Transgender } \\
\text { National Hotline - (888) 843-4564 }\end{array}$ \\
\hline Trans Lifeline - (877) 565-8860 & The Trevor Project - Youth (866) 488-7386 \\
\hline$\underline{\text { GLBT Near Me }}$ & $\underline{\text { Trevor Space - Youth }}$ \\
\hline Point of Pride - Trans support & Lambda Legal \\
\hline
\end{tabular}

For LGBTQ BIPOC

\begin{tabular}{|l|l|}
\hline Call Black Line - 1 (800) 604-5841 & $\frac{\text { Crisis Line for Racial Equity Support - }}{(503) 575-3764}$ \\
\hline Mental Health for Queer and Transgender & Center for Black Equity \\
\hline Communities of Color & \\
\hline$\underline{\text { The National Black Justice Coalition }}$ & BTFA Collective \\
\hline
\end{tabular}

For Black Lives Matter/BIPOC Allies

\begin{tabular}{|l|l|}
\hline$\underline{103 \text { Things White People Can Do for Racial }}$ & $\begin{array}{l}\text { Anti-Racism Project (includes events, } \\
\text { resources, books, articles) }\end{array}$ \\
\hline$\underline{\text { Black Lives Matter - Resources for Allies }}$ & \\
\hline
\end{tabular}




\section{Appendix F}

Trans and Gender-Nonconforming Individuals Killed in 2020

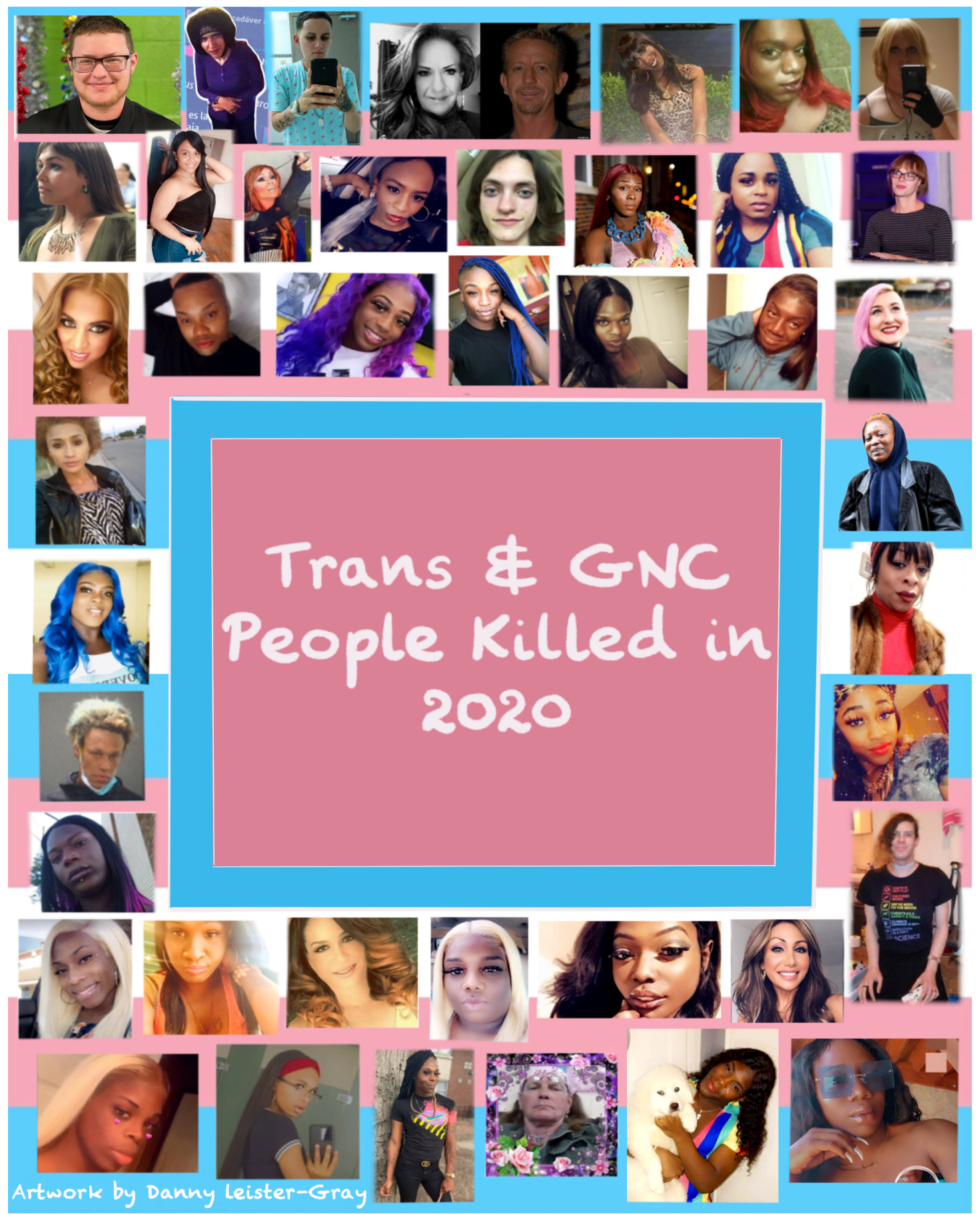

